\title{
SOBRE BUROCRACIAS, DOCUMENTOS E SUJEITOS IMIGRANTES: OTIMIZAÇÃO E FLEXIBILIDADE NA VIVÊNCIA DA MOBILIDADE
}

\author{
On bureaucracies, documents, and immigrants: \\ optimization and flexibility in living mobility
}

Daniel Angel Etcheverry ${ }^{1}$

Resumo. Este trabalho busca aprofundar as experiências de imigrantes perante o poder institucionalizado e a burocracia estatal. Tem como fundamentos teóricos os conceitos de "poder" e "otimização", de Foucault e Aiwha Ong, e de "capital" de Bourdieu. Com base neles procurarei entender como o poder legitimado do Estado e de alguns agentes sociais costuram um tecido social baseado na manutenção e transferência de "capitais". Nesse contexto surge o sujeito "otimizado" e "flexível" como paradigma/exceção, dentro de contextos já não apenas de classe, senão de uma sociedade compartimentada segundo origens nacionais, gênero, situação no mercado de trabalho.

Palavras-chave: migração, mobilidade, otimização, flexibilidade, burocracia, mercado.

Abstract. In this paper I seek to achieve a better understanding of the immigrants experience before the bureaucratic instances. It is founded on Foucault's and Aiwha Ong's concepts of power and optimization, and Bourdieu's notion of capital. On the basis of such concepts, I try to shed light on how the State and human rights agents exercise power by weaving a social tissue on the basis of the maintenance and transference of capitals. In this context, the 'optimized' and 'flexible' individual emerges as a paradigm/exception, not only as a part of the social class context, but mainly in society that is now fragmented according to national, gender and work situation categories.

Keywords: immigration, mobility, optimization, flexibility, bureaucracy, market.

1 Universidade Federal do Pampa (UNIPAMPA). São Borja, RS, Brasil. 


\section{Contextualização}

Este trabalho tem como objetivo apontar para as formas de controle que incidem sobre os sujeitos imigrantes e está baseado em uma pesquisa multifocal para doutoramento em Antropologia Social, realizada junto aos mediadores entre o imigrante e a sociedade de acolhida em três cidades, Porto Alegre, Buenos Aires e Madri². Debruçarei-me mais especificamente sobre a obtenção de documentos e a burocracia como formas de controle dos cidadãos, porém não em uma perspectiva unilateral Estado - sujeito imigrante, e sim mediante a reconstrução do contexto no qual acontece o encontro entre o poder institucionalizado e capilarizado ${ }^{3}$ e os sujeitos individuais em situação de mobilidade ${ }^{4}$.

As transformações ocorridas nas últimas décadas incitaram novas perspectivas para pensar o social, as quais, por sua vez, levam-nos a refletir sobre as novas e as não-tão-novas formas de constrangimento que incidem sobre os sujeitos cidadãos e não-cidadãos. Os constrangimentos já existentes, decorrentes da relação entre o poder estatal e os sujeitos, adquiriram novas configurações com a entrada em cena de novos atores sociais, mas também adquiriram densidade e complexidade na medida em que o conceito de 'liberdade', cada vez mais atrelado à experiência individual, é tensionado pelo interesse que desperta o 'lado obscuro' dessa suposta liberdade, sempre distribuída de forma desigual.

Aihwa Ong ${ }^{5}$ aponta para a existência de duas categorias ideais de liberdade individual no contexto do neoliberalismo: uma liberdade "positiva", que relaciona o indivíduo ao Estado e o coloca na posição de demandante de sua proteção e de um tratamento igualitário em relação aos outros indivíduos e uma liberdade "negativa", que libera o indivíduo do âmbito de influência do Estado, lhe garantindo liberdade de expressão, de movimento e de ação, ou seja, a capacidade de exercer a agência. Neste último pode ser incluída a liberdade de exercer as práticas neoliberais autônomas através das fronteiras. Esses dois tipos de liberdades individuais se articulam de formas diversas nos diferentes contextos.

Ong chama de 'romântica' a forma como a problemática da mobilidade tem sido abordada pela maioria dos autores pós-coloniais. A ênfase tem sido colocada na liberdade de ir e vir através das fronteiras e na existência de redes transnacionais como propiciadoras da realização da liberdade de buscar uma

\footnotetext{
Trata-se de uma pesquisa etnográfica realizada entre fevereiro de 2008 e agosto de 2010. As técnicas empregadas foram entrevistas abertas, observação participante e mapeamento de redes.

3 Na perspectiva foucaultiana, o controle que é exercido sobre os sujeitos, e neste caso os sujeitos migrantes, não está monopolizado nas mãos de um agente único; ele é capilarizado, conseguindo assim penetrar todo o tecido social. Com o termo 'constrangimento', refiro-me às relações de poder que excedem a compreensão dos sujeitos em situações particulares.

4 O termo 'migração' vem carregado de um conjunto de significados e esterótipos que delimitam um espaço mais restrito; por isso, reservo-o para as situações em que é necessário considerar tais aspectos.

5 ONG, Aiwha. Experiments with freedom: milieus of the human.
} 
vida melhor, independentemente das configurações nacionais. No entanto, para a autora, o que realmente estaria havendo é uma retração por parte do Estado de atender às necessidades da população, acompanhada de um incentivo a que os sujeitos ajam independentemente, buscando uma realização própria longe da proteção estatal. O ato de governar, conforme a autora ${ }^{6}$ explicita no artigo mencionado, implica cada vez mais um incentivo à autorrealização baseada no que ela chama de ético-política, o que ela denomina de 'otimização'

Junto com isso, a constante evocação do mercado como o único e inevitável agente regulador da vida social obscurece a percepção das variadas apropriações que dele e do neoliberalismo se fazem em situações e regiões diferentes, e incita reações defensivas que nos impedem perceber que, de alguma forma, pautamos nossas vidas pelas suas exigências. Uma carência na forma como o conceito de mercado é utilizado dificulta que percebamos sua capacidade de penetração de tais exigências. Fala-se do mercado como pertencente exclusivamente ao âmbito das transações comerciais, com resultados mensuráveis apenas em termos de capital econômico.

Bourdieu $^{8}$ nos fala de como as diversas formas de capital -social, econômico, cultural, etc. - são transferíveis e convertíveis umas nas outras. Com base nisso, considero 'mercado' todas as formas de relações sociais baseadas na tentativa de incrementar os diversos capitais. Isso permitiria entender a otimização como uma forma de controle e ingerência na vida dos indivíduos que, mais do que girar em torno de interesses econômicos, aplica a lógica da economia de mercado a todas as áreas da vida dos indivíduos. Assim, otimizar-se é o único caminho para o acúmulo de capitais e ser 'flexível' a forma de transformar um tipo de capital em outro. O termo 'flexibilidade' nos coloca, então, no âmbito das (im)possibilidades e das negociações: aprender a denominá-las - dominá-las - é a incumbência do sujeito melhor otimizado, daquele que não vai aceitar permanecer nos nichos sociais que the foram designados.

Portanto, os conceitos de, 'liberdade', 'mercado', 'otimização' e 'flexibilidade' são importantes para entender as relações de poder que participam da caracterização do imigrante e que o colocam dentro de algum estereótipo no momento do encontro com a burocracia.

\section{Otimização, flexibilidade e caracterização dos imigrantes}

O poder legitimado e infinitamente capilarizado permite que alguns sujeitos, os melhor otimizados, conquistem sua própria forma de inclusão enquanto outros, aqueles que têm uma 'cultura' e não se esforçam para se

\footnotetext{
6 Ibidem.

7 Conceito inicialmente empregado por Foucault em O nascimento da Biopolítica e aprofundado por Aiwha Ong em sua obra, especialmente em Neoliberalsm as exception.

8 BOURDIEU, Pièrre. A distinção: crítica social do julgamento.
} 
livrar dela, permanecem relegados aos nichos de trabalho e convívio social que Ihes são apriorísticamente reservados. É necessário neste ponto ressaltar que os sujeitos etnificados, aqueles que são pensados em termos de sua origem nacional e cultura, são sempre provenientes das classes populares de países menos desenvolvidos economicamente e, portanto, sua 'cultura' é, ao mesmo tempo, um elemento exótico ou pitoresco e um estigma que lhes adjudica um lugar no espectro social. Há ainda outros, os considerados "não-adaptáveis", aqueles que ficam por fora de todas as políticas de inclusão por não apresentarem as características que fariam deles os imigrantes desejáveis.

Nesse contexto considero a 'otimização' como uma forma de regulação. Seguindo a linha de pensamento de Ong, baseio-me na ideia de que é através do favorecimento dos sujeitos elegíveis à inclusão e de uma rede de organizações e saberes que toda forma de poder legitimado banaliza divisões sociais, como se a sociedade fosse reconhecida em parcelas prontamente distinguíveis. Porém, isso se faz não mais excluindo pela fragmentação direta do corpo social, senão estabelecendo parâmetros de elegibilidade compatíveis com princípios mercantilistas.

$\mathrm{Na}$ tentativa de preencher o vazio causado pela retração do estado, agentes sociais variados - agentes dos direitos humanos quase sempre desenvolvem ações objetivadas à inclusão social dos imigrantes e é ai que reside a sua ambiguidade. Embora em seus discursos revindiquem a promoção da igualdade social, muitas das ações promovidas por tais agentes visam, mais frequentemente do que se poderia esperar, à manutenção de uma coesão social, reafirmando a existência de indivíduos mais e menos humanos ${ }^{9}$.

Este é o caso, entre outros, das ações dos mediadores que promovem oficinas e cursos de capacitação para o trabalho. Raramente são tais cursos concebidos no sentido de aproveitar as capacidades dos sujeitos imigrantes. Nas três cidades em que foi realizada esta pesquisa, pude constatar que se, por um lado, os mediadores reproduzem a ideia de que os imigrantes ocupam postos de trabalho de escalão inferior aos que ocupariam em seus países de origem, quase todos os cursos e oficinas que eles promovem estão direcionados à formação de pedreiros, costureiras, faxineiras, empregadas domésticas, encanadores, e assim por diante. Embora existam exceções, dificilmente encontramos cursos de tradutores ou intérpretes, de guias turísticos, de professores da língua materna, em fim, cursos que valorizem e aproveitem a experiência da mobilidade; estão quase sempre destinados a preencher os postos de trabalho que a sociedade de acolhida necessita ${ }^{10}$.

9 CARDARELlO, Andrea, FONSECA, Claudia. Direitos dos mais e menos humanos, p. 85.

10 Há exceções, mas são poucas; encontrei uma organização de apoio a imigrantes em Madri que oferecia, além desses cursos, um curso de tradução da língua árabe ao castelhano e um curso de guia turístico. 
Cabe, nesse sentido, procurar entender quais são as noções de indivíduo e de direito que cada agente maneja nos contextos específicos das relações de poder em que estão inseridos os sujeitos migrantes e os agentes de mediação, neste caso. Estamos pensando no empoderamento de sujeitos individuais, coletivizados ou não, que lhes permita lidar com as forças centrípetas de uma sociedade que gira em torno de si mesma e assim encontrar ou negociar um lugar adequado dentro desse tecido social ou, pelo contrário, estamos pensando em moldar sujeitos que possam se adequar às necessidades dessa sociedade que os suga?

Por isso, no contexto do surgimento de uma multiplicidade de atores sociais, cada um com suas competências e com seus poderes de barganha, o conceito de 'otimização' é central para pensar a construção da subjetividade e das formas de controle social. Daí que as experiências de subjetivação do controle vividas pelos sujeitos migrantes sejam o resultado tanto da imposição dura e bruta do controle da mobilidade administrado pela burocracia quanto da necessidade de otimizar-se e conformar-se a padrões predeterminados de conduta, a qual resulta, por sua vez, na capacidade maior ou menor de forjar um lugar de negociação desse comportamento idealizado.

Partindo desse princípio, pensar o controle do status migratório exercido pelo Estado separadamente de outras formas de controle ao qual os indivíduos estão sujeitados obscureceria a capacidade de compreender que também as relações de poder geram e vinculam situações. Não pretendo, com isso, dizer que todas as formas de poder confluam ou se legitimem nas instâncias burocráticas do Estado que conferem ou não legalidade ao imigrante. É necessário ampliar a percepção da fluidez das diversas formas de exercer o poder sobre os sujeitos migrantes, as quais transitam entre as diversas áreas da vida social, revelando a capilarização desse poder e evidenciando também uma tensão constante entre a manutenção e ampliação de lugares de enunciação sobre o imigrante e a fluidez dos discursos que a partir desses lugares são proferidos.

Veremos, na sequência, as formas como este sujeito supostamente flexível é também alvo de políticas de controle e de otimização perante a burocracia, contrariando qualquer identificação entre flexibilidade e a ideia de liberdade.

\section{As instâncias burocráticas muito além de si mesmas}

Vou refletir agora sobre uma das formas de encontro ${ }^{11}$ entre o imigrante e o poder institucional capilarizado. A burocracia é uma forma de controle pelo Estado, mas não a única. Ela compartilha e disputa o espaço do controle com uma variedade de elementos simbólicos criados a partir de um entendimento compartimentado da realidade. 11 O encontro entre o Estado e o imigrante chega ao ápice do seu dramatismo no momento das
blitzs ou batidas policiais, mas esse é tema para outros trabalhos. 
Esta interação entre o imigrante e o Estado leva a um aprendizado e apropriação das formas de negociação por parte do primeiro, auxiliado frequentemente pelo convívio com seus pares e, principalmente, pela ação dos mediadores, que instigam também atitudes pró-ativas dos imigrantes como empreendedores.

A diferença entre as antigas políticas de assimilação dos imigrantes à sociedade de acolhida e as políticas de otimização a que me refiro acompanha a transformação nas formas de perceber as sociedades chamadas de ocidentais. Quando o estado-nação era percebido pela literatura sociológica como uma unidade indissociável e homogênea, a opção do recém chegado era viver como imigrante estrangeiro até que o tempo e a descendência o incorporassem ao panteão dos personagens constitutivos da nação. O Brasil e a Argentina são dois casos exemplares disso. A integração dos imigrantes à sociedade de acolhida dava-se pela assimilação do imigrantee, como o próprio termo o indica, a vontade do imigrante ficava fora desse processo; não é possível "se assimilar", somente se pode "ser assimilado", o que sugere que o espaço de ação do imigrante era reduzido. Hoje, que a unidade do estado-nação está sempre em questão, que se fala em estados "multinacionais", e que as sociedades tendem a se esfacelar agrupando-se em torno de identidades étnicas, sociais, de classe, de bairro, políticas, de gênero, etc., as formas de integração implicam o acionamento de uma identidade diferenciada que se encaixe nas categorias prefixadas a partir de um entendimento local da diversidade, entre a folclorização e a etnificação do 'outro' e um processo de adaptação extremamente mediado por inúmeras organizações não-governamentais.

Durante o meu trabalho de campo em Madri, uma das situações nas quais me vi envolvido como estrangeiro mostrou-me claramente que o jogo de identidades não tem, como jogo que é, um final previsível, mas que conhecer as categorias empregadas localmente pode ser muito útil.

Nos onze meses que estive na Espanha, fui detido pela polícia quatro vezes. Em todas as quatro ocasiões, minha indumentária era semelhante; costumo vestir roupas casuais, carregar uma pequena bolsa de tiracolo ou mochila, óculos de receita, cabelo medianamente longo e barba curta. No entanto, ao ver minha carteira de estudante emitida pelo estado espanhol para esse período, minha nacionalidade uruguaia e minhas intenções foram questionadas pelo agente de polícia. Nas três primeiras situações, os policiais me perguntaram o que fazia no país, onde e o que estudava, sendo que todas essas informações estavam explícitas na carteira de identidade que eles tinham na mão. Perguntaram também se carregava armas ou drogas, pediram que abrisse minha bolsa. Na quarta ocasião, que teve lugar frente ao monumento a Cristovão Colombo, no centro turístico da cidade de Barcelona, o policial pegou minha carteira de identidade e zombou: "Entonces tu eres uruguayo", 
chamou uma agente que estava com ele na viatura e disse: "Él dice que es uruguayo". Ela não pegou o documento nas mãos; olhou de longe. Mais dois agentes se aproximaram e o primeiro mostrou-lhes também minha carteira de identidade. Olhei para a agente mulher enquanto os outros três falavam e perguntei: "¿Cuando fue construido este monumento a Cristoval Colón?", simultaneamente puxando minha câmara fotográfica do estojo prendido ao cinto e até então coberto pela camisa. Foi então que o primeiro agente me devolveu a carteira de identidade.

Na minha visão, eu poderia ser qualquer estudante da minha geração e origem. Já na visão do policial, uma série de sinais difusos me colocavam em outras categorias; a minha cor de pele e traços eram reservados para os árabes e a mochila poderia significar que eu era vendedor de CDs pirata, já que é isso que imigrantes irregulares árabes fazem; uma carteira de identidade de estudante uruguaio desafiava essa categoria. Foi só quando acionei uma identidade de turista interessado em monumentos, materializando essa identidade na câmara fotográfica, que consegui sair da categoria que o policial se esforçava em me colocar e encaixar-me em outra que ele também conhecia.

Isso tudo mostra a necessidade do imigrante de se definir perante o local nos termos do local; saber jogar com suas categorias e saber até que ponto é bom desafiá-las. Os agentes mediadores poderão auxiliá-lo a desvendar essa trama - o que de fato ocorre com os menos institucionalizados - ou, pelo contrário, induzi-lo a escolher o 'caminho seguro' da adaptação aos lugares sociais para ele previamente reservados ${ }^{12}$.

Na obra supracitada, Ong nos leva a pensar também nos limites dessa flexibilização. Como aponta a autora, nem todos se beneficiam igualmente das facilidades de mobilidade nem da capacidade de acionar recursos simbólicos. A compressão espaço-tempo que muitos autores, especialmente Appadurai, têm entendido como característica da flexibilização, não escapa às lógicas político-econômicas. Se a flexibilização é uma característica dos mercados e dos estados frente a eles, em que medida a flexibilização não é, também, um limite para os sujeitos?

Foucault ${ }^{13}$ aponta como o indivíduo 'flexível' acumula maior capital social e tem um maior número de possibilidades ao seu dispor. Sendo a flexibilidade também uma qualidade apreciável dos sujeitos adaptados às mudanças sociais, ela é também um dos objetivos das políticas explícitas de otimização.

\footnotetext{
${ }^{12}$ As categorias censitárias do Brasil são um exemplo claro disso: branco, preto, pardo, índio e amarelo constituem o leque de categorias raciais e étnicas pensáveis. Quem não se encaixar dentro de uma delas terá que escolher uma dentre as cinco, pois nem sequer a categoria "outra" existe.

${ }^{13}$ FOUCAULT, Michel. El nacimiento de la biopolítica.
} 
Em princípio, poderíamos pensar que o migrante é o sujeito flexível por excelência, na medida em que teve a disposição de trocar de habitat e de enfrentar os desafios de criar um novo espaço em uma sociedade que desconhece.

O sujeito deve ser flexível para se ajustar às necessidades do mercado, o qual the exige presença e prontidão e ignora a realidade concreta destas pessoas. O imigrante deve poder se deslocar geograficamente para cobrir vagas de trabalho, deve estar disposto a pagar taxas elevadas pela regularização de seus documentos e, ainda mais, saber negociar seu tempo a fim de poder dar andamento aos trâmites de regularização, já que os horários de funcionamento das instituições burocráticas coincidem com os horários de trabalho, quase sempre; deve provar que tem um domicílio fixo, mesmo que alugar moradia implique apresentar documentos que estão fora do alcance de quem está iniciando a criar suas redes sociais na cidade.

Assim como o deslocamento não é meramente geográfico, a flexibilização vai muito além da capacidade de transitar entre países. Fundamentalmente, os sujeitos devem aprender a lidar com as burocracias, fazendo de si mesmos aquilo que, em situações pontuais, se exige.

A figura do imigrante termina sendo quase sempre o resultado de uma superposição de categorias rígidas, em certo sentido, e negociáveis dentro de certos limites. Em Cartographies of Diaspora, Avtar Brah ${ }^{14}$ nos faz pensar na força das classificações, que leva à necessidade de encaixar os sujeitos em determinadas classificações, as quais nem sempre correspondem às percepções dos sujeitos que migram. Os sujeitos deslocados terminam assumindo como próprias categorias de classificação que não pertencem a seu universo simbólico, a fim de poder estabelecer um diálogo com qualquer instância superior, seja ela o Estado, uma organização que deve representá-lo - os mediadores -, ou os policiais, em uma abordagem de rua. O oficial da embaixada britânica na Uganda exigia que Brah escolhesse entre se declarar ugandesa ou paquistanesa, tendo que escolher entre um fenótipo que a denunciava asiática e uma história de vida que a ligava a ambas as nações, e isso implicava ter que renunciar imediatamente a uma pluralidade de experiências que a constituía enquanto sujeito particular, para poder dialogar com uma instância burocrática incapaz de lidar com a ambivalência do 'outro'.

\section{A (ir)regularidade do imigrante}

Um outro aspecto desse encontro refere à (i)rregularidade do sujeito imigrante. É comum hoje escutar que os estados facilitam ou fazem vista grossa à entrada de imigrantes de forma irregular quando o mercado de trabalho interno precisa deles, e que se espera que eles voltem aos seus países quando

${ }^{14}$ BRAH, Avtar. Cartographies of diaspora: contesting identities. 
as circunstâncias são outras. Esse argumento é comum, sobretudo na voz dos mediadores, quando se trata de pensar e defender a humanidade dos migrantes.

Aihwa Ong $^{15}$ nos leva a pensar como o recurso de portar múltiplos passaportes, a possibilidade de obter uma cidadania do país de chegada e todas as formas de adaptação das burocracias estatais às exigências da transnacionalização da produção de bens de consumo têm resultado em uma flexibilização do conceito de cidadania, tanto por parte dos migrantes como por parte da literatura sobre o tema. A cidadania estaria cada vez menos atrelada a um lugar de nascimento e pertença e teria se tornado instrumental nas tentativas de acúmulo de capital material e social. Semelhantemente, em seu estudo sobre os migrantes palestinos no sul do Brasil, Denise Jardim ${ }^{16}$ mostra como a posse de vários passaportes faz parte de um universo de possibilidades de circulação que se apoia nas redes de parentesco transnacionalizadas. Nesse sentido, a posse de vários passaportes redunda em um aumento do capital social frente aos outros membros da própria coletividade e aos locais não-palestinos.

Os Estados regulam a partir de lugares de poder muito distantes dos balcões de negociação ${ }^{17}$ e por isso os mediadores são melhor compreendidos não somente como terceirizadores do Estado, mas como manejadores de discrepâncias. O imigrante mais do que o agente da burocracia é quem deve entender e aprender a lidar com as formas de transmissão do poder do Estado, já que é ele que tem interesse que a relação com o agente da burocracia redunde em uma situação que the seja favorável ${ }^{18}$.

John Torpey ${ }^{19}$ demonstra, em um estudo histórico sobre a invenção do uso de passaportes, como o monopólio estatal do direito a autorizar e a controlar a circulação de pessoas é inerente à própria formação dos estados desde o colapso do absolutismo, envolvendo vários aspectos que se reforçam mutuamente: a codificação de leis que estabelecem quais tipos de pessoas podem circular no interior de cada estado e atravessar suas fronteiras, os lugares por onde essa travessia pode ser feita e, sobretudo, a identificação sem ambiguidades de todas as pessoas. Para isso foi necessário criar documentos reconhecidos mutuamente por burocracias destinadas a implementar esse regime de identificação, o qual

${ }^{15}$ ONG, Aihwa. Flexible citizenship: the cultural logics of transnationality.

${ }^{16}$ JARDIM, Denise. Palestinos: As redefinições de fronteiras e cidadania.

17 Num nivel supra-nacional, as burocracias estatais também lidam com a migração a partir de acordos entre os governos dos estados nacionais. É o caso da denominada 'ampliação das fonteiras', e o caso mais conhecido é aquele dos acordos entre os estados da UE e aqueles do norte da África para impedir que imigrantes subsaarianos entrem em seus territórios e assim possam ter facilitado o acesso aos paises da UE.

${ }^{18}$ Em "A documentação de estrangeiros no Brasil, seus caminhos e significados" mostro as dificuldades enfrentadas pelos imigrantes na obtenção de documentos, e analiso o signficado dos mesmos. O documento é uma das perspectivas através das quais os imigrantes avaliam sua experiência migratória (p. 119-139).

${ }^{19}$ TORPEY, John. A invenção do passaporte. Vigilância, cidadania e o Estado. 
inclui desde documentos para identificação dos nacionais até passaportes que permitem a circulação entre estados e, com crescente frequência atualmente, medições biométricas e tecnologias de identificação e singularização dos sujeitos.

$\mathrm{Na}$ maioria das cidades europeias, esse controle dos cidadãos baseia-se no procedimento chamado "empadronamento", ou seja, o registro dos domicílios de todos os cidadãos, que é incorporado à vida dos cidadãos como um elemento básico da cidadania, permitindo o acesso aos serviços básicos de saúde, educação, etc. Ninguém existe sem estar empadronado, ou seja, fora do controle e proteção do Estado. Empadronar-se é um direito e um dever, é o princípio básico de inclusão, para um nacional ou para um estrangeiro. O empadronamento é a face mais visível de uma burocracia compartilhada entre nacionais e imigrantes.

No Brasil e na Argentina, os cidadãos nacionais não precisam registrar seu domicílio, mas as leis migratórias de ambos países determinam que o estrangeiro assim o faça. Isso, em princípio parece mais um elemento discriminatório, uma necessidade de colocar a vida do estrangeiro sob o controle do Estado em um ato de discriminação em relação aos nacionais. E, de fato, essas parecem ser suas intenções se levarmos em conta o Estatuto do Estrangeiro no Brasil. Apesar disso, nem o estado brasileiro nem o argentino têm o controle preciso sobre onde o imigrante mora, pelo simples fato de que a maioria dos migrantes não declara onde reside senão nos momentos em que precisa tramitar documentos frente junto às autoridades migratórias. Do mesmo modo, os nacionais não declaram seu domicílio a não ser em situações pontuais. No Brasil, uma conta de luz ou água com o nome é o certificado de sua localização para qualquer expediente comercial ou demanda pública. O Cadastro de Pessoa Física (CPF) tem se tornado a forma de localizar e dar existência ao sujeito perante o Estado.

Isso tudo põe em relevo o fato de que as burocracias estatais não seguem uma lógica cartesiana segundo a qual a causas iguais correspondem consequências iguais. Por um lado, existe uma crescente tendência à unificação das formas de identificar e localizar os indivíduos, no caso da União Europeia (UE), com um sistema de empadronamento comum a todos os estados nacionais, a aplicação de uma política comum de vistos e uma tendência por parte dos governos nacionais a seguir as diretrizes das políticas migratórias consensuadas no nível supra-nacional da UE. Por outro lado, os estados têm encontrado soluções particulares para um problema que é inerente à existência do estado-nação, qual seja, a necessidade de conhecer e controlar os sujeitos que habitam seu território, o que remete a uma forma de controle sobre os corpos dos indivíduos.

Isso tudo nos leva a considerar a possibilidade de que a irregularidade do sujeito em situação de mobilidade não esteja confinada a um momento 
de sua história pessoal; as políticas de otimização fazem parte do conjunto de constrangimentos que se impõem sobre os sujeitos imigrantes, seus corpos e formas de relação, equalizando irregularidade e inadequação no contexto do cotidiano. O corpo, os jeitos de andar e gesticular, o sotaque, sua indumentária, esses e outros elementos denunciam sua 'irregularidade' - inadequação -, mesmo quando seu status migratório é regular. Será, então, que estamos falando de dois âmbitos separados de controle, uma outorgando e negando documentos e, com isso, garantindo o acesso a determinados benefícios e, a outra, pautando as formas de viver, trabalhar, vestir e andar dos sujeitos por parte da sociedade?

\section{Documentos e lugares de enunciação}

As observações realizadas na pesquisa que fundamenta este trabalho sugerem que a concessão ou recusa de documentos a imigrantes estrangeiros está permeada pela premissa de que o imigrante é alguém que precisa estar sob controle. Por outro, a posse de um documento não se esgota em si mesma. Uma carteira de identidade ou um passaporte tem a capacidade de evocar, transformar e ressignificar os discursos sobre identidade, pertença, inclusão ou exclusão. O documento tem o poder de ampliar o campo discursivo, tanto pelo direito ao pronunciamento que confere ao sujeito - o documento confere existência ao sujeito, Ihe dá a palavra - como pelo deslocamento de lugar de enunciação e, consequentemente, de paradigma, que ele implica. A obtenção de documentos implica passar de um "estar fora" a um "estar dentro" do estado-nação, pelo menos no aspecto formal das relações.

Assim, recusar-se a outorgar um documento implica negar ao sujeito imigrante um lugar de enunciação. Em princípio, ele está fora da abrangência do Estado, mas não totalmente, na medida em que a distribuição de recursos baseia-se na existência de mais e menos humanos, reservando para os menos humanos lugares dentro do estrato social com os quais os mais humanos não querem ser identificados. O imigrante em situação irregular serve de paradigma negativo aos imigrantes em situação regular porém sujeitos a voltar à irregularidade devido, por exemplo, ao não pagamento de suas contribuições, como ocorre na Espanha. Por isso, o imigrante em situação irregular é necessário ao Estado. Isso faz também com que a completa negligência de suas necessidades básicas seja frequentemente mais temida do que real e que o debate em torno dos direitos dos imigrantes irregulares aos serviços básicos - somente emergenciais - de saúde e à educação dos filhos nunca deixe de estar sobre a mesa. Na perspectiva do biopoder, a negligência não é uma falta de cálculo que resulta na exclusão de pessoas 'inadaptadas' ou em situação migratória irregular. É, sim, a expressão de que algumas pessoas têm "humanidade" e são portanto, merecedoras de atenção, e outras não. 
Nessa perspectiva também, a concessão de documentos implica a designação de um lugar de discurso dentro de um conjunto fechado de possibilidades. Fechado em função da hierarquização dos status migratórios. Residentes temporários, residentes permanentes e naturalizados têm direitos e vulnerabilidades diferenciados entre si e em relação aos nacionais e, consequentemente, lugares de enunciação individualizados. Isso não implica, entretanto, uma imobilidade. Ter documentos está em algum lugar entre uma concessão do Estado e uma conquista do sujeito, e o próprio trânsito de fora para dentro redunda em um acúmulo de experiências que o sujeito poderá reorganizar de forma a desafiar os limites de seu campo de possibilidades discursivas.

Isso aponta também as fronteiras e os limites da otimização no campo da relação entre sujeitos e a burocracia estatal. Se, de um lado, a nacionalidade do país de residência é colocada como o prêmio aos sujeitos que conseguem a integração plena à sociedade de acolhida, ela funciona também como o limite das possibilidades; há direitos que são reservados aos nacionais por nascimento, sobretudo no que diz respeito à vida política. No processo, o sujeito deverá mostrar que é flexível o suficiente para poder navegar tanto no âmbito da vida em sociedade como na esfera burocrática. A burocracia estatal parece manejar dois códigos; embora os critérios explícitos para a regularização, a transformação de um visto de residente temporário em um visto de residente permanente e a naturalização estejam no âmbito do formal, a avaliação dos documentos apresentados, o tempo de demora e a decisão final constituem momentos de concretude nos quais o imigrante tem pouco ou nenhum controle. Durante os processos de regularização e naturalização é elaborado um relatório sobre o candidato, mas os critérios e o conteúdo dele não estão a sua disposição, nem a dos pesquisadores.

Estando em Madri, entrei em contato com um rapaz de Ghana que havia apresentado um contrato falso de trabalho elaborado pelo proprietário equatoriano de uma loja de roupas mediante o pagamento de dois mil euros. A solicitação de residência temporária foi-lhe negada com base no argumento de que o contrato não tinha as informações necessárias. No entanto, seu primo apresentara um contrato idêntico - eu vi ambos os contratos - e foi aceito.

Isso sugere que há caminhos dentro da burocracia que são desconhecidos a quem está de fora, e que transitar por eles é um exercício que leva algum tempo de aprendizagem e um deslocamento de perspectivas, um olhar "por cima do ombro" do burocrata. Nesse sentido, a flexibilidade necessária à otimização, não é apenas em tempo, organização e disposição para deslocamentos geográficos, mas também uma forma de desprendimento do lugar de enunciação adjudicado para um espaço intersticial onde discursos diferentes podem ser acionados situacionalmente. A arbitrariedade da burocracia tem sido tida e banalizada como "soberania" na admissão de imigrantes, como se 
a administração seguisse realmente uma lógica "cartesiana" e fosse totalmente previsível, quando, na realidade, a relação entre sujeitos imigrantes - e também nacionais - e as instâncias burocráticas é também uma relação semântica ${ }^{20}$.

As observações do trabalho de pesquisa sugerem também que, embora não se possa negar o lado "envolvente" do poder de controle mediante a burocracia, esse poder não é um dado a priori. Se assim o fosse, seria muito mais fácil lidar com ele, seria escancaradamente autoritário e não provocaria grandes polêmicas. A simples pertença não implica uma forma única e imutável de sujeição, nem o controle por parte da burocracia estatal se limita à emissão de documentos. Não há dúvida que o poder sobre a concessão de documentos implica um cerceamento das liberdades dos sujeitos que os requerem, mas o exercício do poder e de controle pelas instâncias burocráticas não é apenas a instrumentalização de um conjunto de prerrogativas; mais do que isso, se trata de um entrelaçamento confuso de incumbências e imperativos que os sujeitos migrantes devem desenredar "situacionalmente". Ou seja, na perspectiva do agente estatal, seja qual for sua função, ele mesmo está encarregado de manobrar uma situação conforme diretrizes frequentemente contraditórias entre si, ao passo que imbuído de uma autoridade que o coloca em uma situação, digamos por enquanto que vantajosa. Na perspectiva do sujeito migrante, ele precisa aprender os caminhos de uma burocracia obscura, aprender a lidar com situações concretas que excedem as estipulações das leis. Sobretudo, o sujeito imigrante otimizado saberá usar as categorias identitárias locais para poder negociar desde lugares mais vantajosos. Deverá saber ser o que se espera de ele e, mais ainda, surpreender positivamente o agente estatal.

Nesse sentido, mais do que agentes movidos por uma racionalidade burocrática ao estilo weberiano, os funcionários e agentes do Estado aparecem exercendo o poder dentro de um âmbito da vivência social que assim o permite e estimula. Isso não quer dizer que não exista uma racionalidade agindo como motor da máquina burocrática e repressora, mas esta não chega às pontas em estado puro, senão através de uma dinâmica relacional à qual confluem um "habitus" institucional e um "momentum" civilizatório, ou seja, como na visão de Herzfeld ${ }^{21}$, a relação entre burocratas e solicitantes está permeada pelos universos simbólicos de ambos.

Na perspectiva do migrante, então, um conjunto de estipulações se sobrepõem. No convívio com outros imigrantes, com associações e com os mediadores, aprendem que é necessário discernir o alcance das leis da prática do agente. Quase todos os mediadores em Madri têm, entre suas atividades, a

\footnotetext{
${ }^{20}$ HERZFELD, Michael. The social production of indifference. Exploring the Symbolic roots of western bureaucracy.

${ }^{21}$ Ibidem.
} 
implementação de oficinas de esclarecimento sobre a lei migratória, sobre as formas de obter documentos e, o que é mais interessante, sobre as estratégias e táticas que os migrantes devem aprender para lidar com a burocracia e com a polícia. Já em Buenos Aires e em Porto Alegre, este tipo de informação é transmitido individualmente e os mediadores tendem a ser muito mais reservados quanto ao aconselhamento das práticas que os migrantes podem acionar frente à lei e à autoridade.

\section{Conclusão}

Tudo o que foi apresentado neste artigo aponta para a ambivalência das políticas de otimização que permeiam todas as esferas do poder capilarizado; neste caso, escolhi as instâncias burocráticas e os mediadores para evidenciar como, o poder regulador age de tal forma que seja impossível separar as experiências perante a burocracia dos outros aspectos da vivência migratória.

A necessidade de saber como recriar e acionar identidades preconcebidas, de se mostrar apto e disposto a ser moldado pelas necessidades locais e sabendo, em maior ou menor medida, jogar e conjugar as capacidades e os anseios próprios com as expectativas da sociedade de acolhida, reconhecendo e empregando as categorias locais e aprender a desatar os nós da burocracia, a reconhecer suas lógicas subjacentes e a transitar por seus caminhos obscuros, isso tudo faz parte do conjunto de habilidades que o imigrante otimizado, flexível deve cultivar.

Para culminar, a hipótese que busquei demonstrar é que, para além das contradições internas à burocracia e da permeabilidade desta aos universos simbólicos dos agentes individuais envolvidos, as instâncias burocráticas são lugares onde a otimização é legitimada como o ideal que deve nortear as vidas dos sujeitos; estes devem aprender a conhecer e a lidar com aqueles aspectos do universo burocrático que não estão escritos nem formalizados, escapando ao âmbito do previsível. Entretanto, o universo burocrático e suas demandas não podem ser considerados independentemente dos outros constrangimentos que incidem sobre os sujeitos; como apontei acima, a otimização atua de maneira ambígua, de um lado estimulando os sujeitos a se apropriarem de seus destinos e, do outro, estabelecendo parâmetros de elegibilidade crescentemente elevados, deixando assim muitos sujeitos fora do guarda-chuva das políticas de inclusão. Quem é flexível o suficiente para transformar uma forma de capital em outra poderá, com um pouco de sorte, forjar um lugar para si fora dos nichos reservados aos imigrantes, ao custo de ter que se deixar moldar, física e simbolicamente pelas forças do mercado. A recompensa pode ser boa e o preço é alto. 


\section{Bibliografia}

BOURDIEU, Pièrre. A distinção: crítica social do julgamento. Porto Alegre: Zouk, 2007.

BRAH, Avtar. Cartographies of diaspora: Contesting identities. Londres: Routledge, 1997.

CARDARELLO, Andrea; FONSECA, Claudia. Direitos dos mais e menos humanos. Horizontes antropológicos, n. 10, ano 5, 1999, p. 83-121.

ETCHEVERRY, Daniel. A documentação de estrangeiros no Brasil: seus caminhos e significados. In JARDIM, Denise (org.). Cartografias da imigração: Interculturalidade e políticas públicas. Porto Alegre: Editora da UFRGS, 2007.

FOUCAULT, Michel. El nacimiento de la biopolítica: Curso en el College de France (1978-1979). Buenos Aires: Fondo de Cultura Económica, 2007.

HERZFELD, Michael. The social production of indifference: Exploring the Symbolic roots of western bureaucracy. Chicago: The University of Chicago Press, 1993.

JARDIM, Denise. Palestinos: As redefinições de fronteiras e cidadania. Horizontes Antropológicos, n. 19. ano 9, 2003, p. 223-243.

ONG, Aihwa. Experiments with freedom: Milieus of the human. American literary history, n. 18, 2006, p. 229-244.

ONG, Aihwa. Neoliberalism as exception: mutations in citizenship and soverignity. Londres: Duke University Press, 2007.

ONG, Aihwa. Flexible citizenship: the cultural logics of transnationality. Londres: Duke University Press, 2006.

TORPEY, John. A invenção do passaporte. Vigilância, cidadania e Estado. Lisboa: Temas e debates, 2003.

Recebido para publicação em 30.06.2015

Aceito para publicação em 29.01.2016

Received for publication in June $30^{\text {th }}, 2015$ Accepted for publication in January 29 ${ }^{\text {th }}, 2016$

ISSN impresso: 1980-8585

ISSN eletrônico: 2237-9843

http://dx.doi.org/10.1590/1980-85852503880004708 